\title{
A decade of anti-IL-1 therapy in CAPS - a spectrum of efficacy in this spectrum of diseases
}

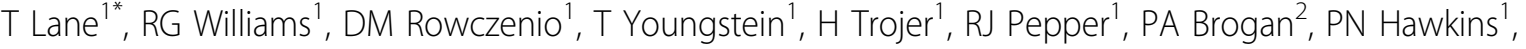 \\ HJ Lachmann ${ }^{1}$ \\ From 8th International Congress of Familial Mediterranean Fever and Systemic Autoinflammatory Diseases \\ Dresden, Germany. 30 September - 3 October 2015
}

\section{Introduction}

Discovery of the role of the IL-1 inflammasome in CAPS has revolutionised treatment, and anti-IL-1 therapies have successfully switched off disease activity in many patients. More than 110 CAPS patients (including 24 children) in the UK have been treated with drugs targeting IL-1, over $90 \%$ of these have had complete resolution of disease.

\section{Objectives}

We describe a cohort of 10 patients who had sub-optimal response to canakinumab and/or anakinra.

\section{Patients and methods}

Patients were diagnosed by genetic sequencing and clinical assessment. Serial SAA concentrations were analysed, along with patient reported symptom scores. Partial response was defined as improved but incomplete resolution of patient-reported symptoms and/or reduction, but not normalisation, of SAA concentration.

\section{Results}

Patients 1 (male; age at treatment: 40; mutation in NLRP3: T436I; phenotype: CINCA) and 2 (female; 43; R260W; MWS) experienced modest and transient reductions of SAA and symptoms when treated with canakinumab. Both patients developed marked inflammation with morphea-like rash shortly afterwards. Both were switched to anakinra with excellent effect.

Patient 3 (male; 47; A439V; FCAS) weighed 130kg, had a partial response to both $300 \mathrm{mg}$ canakinumab q8w and $200 \mathrm{mg}$ anakinra daily. Patients 4 (female; 1; Y570F; CINCA), 5 (male; 16; S547C heterozygote; CINCA) and 6 (female; 59; Y547C mosaic; atypical) had severe disease.

${ }^{1}$ University College London, National Amyloidosis Centre, Division of Medicine, London, UK

Full list of author information is available at the end of the article
Patient 4, experienced partial response to canakinumab and anakinra, although feels better on $300 \mathrm{mg}$ canakinu$\mathrm{mab}(10 \mathrm{mg} / \mathrm{kg} \mathrm{q} 8 \mathrm{w})$. Patient 5 has not responded to $10 \mathrm{mg} / \mathrm{kg}$ q8w canakinumab started 12 weeks ago. Patient 6 has been treated with both canakinumab and anakinra over 10 years, at times concurrently. She experienced a severe flare with aseptic meningitis after attempted conversion to canakinumab. She is now on anakinra $300 \mathrm{mg}$ daily and inflammation and headaches have remained consistent.

Patients 7 to 10 had CNS inflammation symptomatically, and on lumbar puncture/MRI. Patients 7 (male; 41; T348M; CINCA) and 8 (female; 20; A352T; CINCA) had resolution of most CAPS symptoms and SAA normalised on canakinumab $300 \mathrm{mg} \mathrm{q} 8 \mathrm{w}$, however headaches and fatigue continued. Both had previous strokes attributed to CNS inflammation. Patient 7 had some improvement on anakinra. Patient 9 (male; 48; E567K mosaic; atypical), weighing $102 \mathrm{~kg}$, had complete resolution of most CAPS symptoms and SAA normalised, but headaches, poor balance and fatigue continued on both treatments. Patient 10 (male; 24; T348M; MWS) had a complete normalisation of inflammatory markers and peripheral symptoms on $300 \mathrm{mg}$ canakinumab. However, headaches and fatigue remained. Encouragingly, in patients 9 and 10 fatigue and mood have improved after over 5 years of treatment.

\section{Conclusion}

Patients 1 and 2 raise the possibility of IL- $1 \alpha$ mediated inflammation. Patients 3-6 suggest incomplete blockade of IL-1 activity with the maximum doses available on the NHS. Finally in patients 7-10 who had decades of CNS inflammation prior to treatment, headache and fatigue linger. 


\section{Authors' details}

'University College London, National Amyloidosis Centre, Division of

Medicine, London, UK. ${ }^{2}$ University College London, Paediatric and

Adolescent Rheumatology, Institute of Child Health, London, UK.

Published: 28 September 2015

doi:10.1186/1546-0096-13-S1-065

Cite this article as: Lane et al: A decade of anti-IL-1 therapy in CAPS - a spectrum of efficacy in this spectrum of diseases. Pediatric Rheumatology 2015 13(Suppl 1):065.

Submit your next manuscript to BioMed Central and take full advantage of:

- Convenient online submission

- Thorough peer review

- No space constraints or color figure charges

- Immediate publication on acceptance

- Inclusion in PubMed, CAS, Scopus and Google Scholar

- Research which is freely available for redistribution

Submit your manuscript at www.biomedcentral.com/submit

() BioMed Central 